\title{
Autonomia e solidariedade na disposição de órgãos para depois da morte
}

\author{
Ana Carolina Brochado Teixeira* \\ Carlos Nelson Konder**
}

\begin{abstract}
RESUMO:
O presente estudo se debruçará sobre o embate entre liberdade e solidariedade ou, em outras palavras, entre ordem pública e autonomia privada no direito civil contemporâneo, com especial destaque para a solução dessa controvérsia nos atos existenciais. Tomamos como principal exemplo a antinomia hoje existente entre o art. 14 do Código Civil e a Lei 9.434/97, no que se refere à autonomia ou heteronomia na decisão de doar os órgãos.
\end{abstract}

PALAVRAS-CHAVE: liberdade, autonomia privada, solidariedade, funcionalização, doação de órgãos, sucessão

\section{ABSTRACT:}

This paper dedicated to the conflict between freedom and solidarity, individual autonomy and public order, in contemporary civil law, specifically in regard of non-patrimonial acts, centered in the example of the antinomy between Brazilian laws regarding the decision of donating organs for transplant.

KEY WORDS: freedom, autonomy, solidarity, organs donation.

A family is a tyranny ruled over by its weakest member.

- George Bernard Shaw

\section{A autonomia privada entre liberdade e solidariedade}

Entre os grandes desafios do direito civil contemporâneo certamente tem lugar de destaque a questão da autonomia privada. No direito civil tradicional, construído essencialmente ao longo dos séculos XVIII e XIX, a autonomia da vontade era o princípio fundamental de todo o sistema. Imponderável, quase absoluta, ela só sofria restrições de origem externa e, sempre, excepcionais. ${ }^{1}$ Inspirado no ethos burguês revolucionário, o modelo visava consagrar a plena liberdade individual frente ao sistema anterior,

\footnotetext{
* Doutora em Direito Civil pela UERJ. Mestre em Direito Privado pela PUC/MG. Especialista em Direito Civil pela Universidade de Camerino (Itália). Professora de Direito Civil no Centro Universitário UNA. Advogada. Diretora do Instituto Brasileiro de Direito de Família - IBDFAM.

** Doutor e mestre em Direito Civil pela UERJ. Especialista em Direito Civil pela Universidade de Camerino (Itália). Professor adjunto de Direito Civil da UERJ e da PUC-Rio.

${ }^{1}$ Sobre esta concepção de autonomia privada, v. Ana PRATA. A tutela constitucional da autonomia privada. Coimbra: Almedina, 1982.
} 
caracterizado por um Estado absoluto e uma sociedade rigidamente separada em estamentos.

Em virtude disso o sistema estava calcado em uma divisão fundamental: de um lado o direito privado, com o objetivo de garantir o livre jogo das vontades e proporcionar a regulação da sociedade através do "inteligente egoísmo" que guiava o mercado; de outro lado, o direito público, com o objetivo de controlar os poderes do Estado de modo a impedir que ele interferisse nos espaços dos indivíduos e perturbasse o delicado equilíbrio a "mão invisível" - do mercado sobre o qual se firmava a própria sociedade civil. ${ }^{2}$

Instalado no poder, o ideal de emancipação do sujeito, de inspiração iluminista, se converteu em uma concepção de liberdade individualista, voluntarista e patrimonialista. A versão de autonomia privada positivada se pautava em uma visão do homem isolado ("homo clausus"), concebido de forma abstrata (o "sujeito de direito"), que não correspondia às reais condições de vida. ${ }^{3}$ Esta autonomia era julgada apenas com base na formal manifestação de vontade: assinado o contrato sem algum dos defeitos tipificados (erro, dolo, coação), tornava-se o sujeito refém de sua própria declaração. Garantia-se a liberdade formal para vender, alugar, emprestar a juros, sem que fossem fornecidas as condições materiais necessárias para a efetiva fruição de tais liberdades. ${ }^{4}$

As crises econômicas e as atrocidades cometidas pelos regimes nazi-fascistas impuseram uma mudança de paradigma no sentido da proteção prioritária da dignidade da pessoa humana. Consagrada nas declarações internacionais de direitos humanos e na positivação de direitos fundamentais nos textos constitucionais, a dignidade transforma-se em princípio a impor proteção plena da pessoa, em todos os seus aspectos. A sua real emancipação não ocorre através da garantia de uma liberdade formal de declarar vontade, mas através do que se convencionou chamar "livre desenvolvimento da personalidade". 5

\footnotetext{
${ }^{2}$ Gustavo TePedino. Temas de direito civil, 3. ed. Rio de Janeiro: Renovar, 2004, p. 223. Na descrição de Giselda Maria Fernandes Novaes HIRONAKA, "estava consagrado assim o espírito da época: o individualismo jurídico-liberal, a dicotomia entre direito público e direito privado e a garantia da liberdade dos indivíduos" (Tendências do Direito Civil no Século XXI. Revista Trimestral de Direito Civil, v. 10, abr.-jun./2002, p. 214).

${ }^{3}$ Luiz Edson FACHIN. Teoria crítica do direito civil. Rio de Janeiro: Renovar, 2000, pp. 11 e ss.

${ }^{4}$ Para uma análise das acepções de liberdade e autonomia privada v., entre nós, Daniel SARMENTO. Diretos fundamentais e relações privadas. Rio de Janeiro: Lumen Juris, pp. 173 e ss.

${ }_{5}^{5}$ As recentes aplicações do termo - que tem origem na Lei Fundamental alemã, art. ${ }^{\circ}$, I. - são descritas por Claus-Wilhelm CANARIS. A influência dos direitos fundamentais sobre o direito privado na Alemanha. In Ingo Wolfgang SARLET (org.). Constituição, direitos fundamentais e direito privado. Porto Alegre: Livraria do Advogado, 2003, pp. 223-243.
} 
Sob este novo paradigma se destaca que não existe liberdade em abstrato: toda autonomia é constituída a partir da sociedade dentro da qual o sujeito constrói a sua própria identidade, na constante convivência com o outro (a alteridade). ${ }^{6}$ Só existe verdadeira autonomia no âmbito de uma situação jurídica determinada, no diálogo entre fato e norma que considera a pessoa em suas peculiaridades, tutela suas vulnerabilidades e assim garante que ela tenha efetivas condições de um exercício pleno da sua liberdade. Neste sentido, já se afirmou que, “melhor do que individuar 'o' fundamento constitucional da autonomia contratual é pesquisar 'os' fundamentos constitucionais da autonomia negocial". ?

O principal destaque está na implementação de um tratamento diferenciado para a autonomia relativa a atos existenciais, isto é, para realização de escolhas ligadas não ao patrimônio, mas àqueles elementos que constituem a identidade que individualiza e caracteriza cada ser humano. Como ressalta Pietro Perlingieri:

O ordenamento não pode formalisticamente igualar a manifestação da liberdade através da qual se assinala, profundamente, a identidade do indivíduo com a liberdade de tentar perseguir o máximo lucro possível: à intuitiva diferença entre a venda de mercadorias [...] e o consentimento a um transplante corresponde uma diversidade de avaliações no interno da hierarquia dos valores colocados pela Constituição. ${ }^{8}$

Por isso, é fundamental se refletir sob esse viés existencial da autonomia privada, qualitativamente diferente da sua vertente patrimonial. Isto porque as situações jurídicas subjetivas patrimoniais, tendo em vista sua instrumentalidade indireta para a realização da dignidade da pessoa humana, devem desempenhar uma função social para serem merecedoras de tutela. Em virtude disso, a autonomia privada patrimonial pode sofrer limitação em virtude do princípio da solidariedade de uma forma mais acentuada, funcionalizada à realização também de interesses coletivos.

Já as situações jurídicas subjetivas existenciais, por serem manifestações diretas da personalidade como valor, não podem ser instrumentalizadas. Assim, no que se refere à autonomia privada existencial, para que se garanta o livre desenvolvimento da personalidade, é fundamental que a pessoa possa escolher a forma de vida que mais lhe

\footnotetext{
${ }^{6}$ Maria Celina Bodin de MoRAES. O princípio da solidariedade. In: Manoel Messias Peixinho, Isabella Franco Guerra e Firly Nascimento Filho (orgs.). Os princípios da constituição de 1988. Rio de Janeiro: Lumen Juris, 2001, p. 169.

${ }^{7}$ Heloísa Helena BARBOzA. Autonomia em face da morte: alternativa para a eutanásia? In Tânia da Silva Pereira et al. (coord.). Vida, morte e dignidade humana. Rio de Janeiro: GZ, 2010, p. 38.

${ }^{8}$ Pietro PerlingIERI. Perfis do direito civil. Rio de Janeiro: Renovar, 1997, p. 276.
} 
realize, bem como concretize o seu projeto de vida individual. Por isso, nesse campo, não se pode afirmar que a autonomia seja funcionalizada, ainda mais a interesses sociais ou coletivos. Se se pensar na funcionalização da autonomia privada existencial, a única alternativa possível é lhe atribuir uma função pessoal, individual, vinculada exclusivamente à livre realização da personalidade. ${ }^{9}$

\section{O respeito à autonomia existencial: pluralismo democrático, identidade pessoal e privacidade}

A proteção a esta autonomia existencial ganha especial relevo no contexto de uma sociedade diversificada. Reconhece-se de forma ampla que a sociedade contemporânea não é marcada pela homogeneidade e pela semelhança, mas sim pela diversidade e pela diferença, cabendo-lhe o desafio de lidar com todas as consequiências decorrentes deste fato. Neste debate, é necessário afastar as visões reacionárias e autoritárias que tendem a combater e reprimir este fenômeno e, em seu lugar, reconhecer que a tolerância e o diálogo tornam a diversidade uma benesse para o enriquecimento cultural de qualquer comunidade.

Não se pode deixar de verificar que, mesmo dentro desta perspectiva de acolhimento do pluralismo, diferentes visões se embatem sobre como exatamente deve ser a postura do direito para estabelecer o diálogo e, nos pontos necessários, o consenso entre as distintas concepções de bem ou identidades partilhadas pelos destinatários do ordenamento. Mas desde visões mais liberais, na linha de uma imparcialidade da justiça frente à diversidade, até visões mais comunitaristas, em compromisso com uma visão substantiva de tolerância, passando ainda por uma perspectiva dita democráticodeliberativa, de construção discursiva do direito, todas podem ser acolhidas como premissa, enquanto partilharem da idéia comum de respeito à diversidade de orientações. ${ }^{10}$

Foi este o caminho trilhado pelo nosso ordenamento. Ao constituir-se como Estado Democrático de Direito, nossa Constituição tomou como fundamento o pluralismo político $\left(\mathrm{CF}\right.$, art. $\left.1^{\mathrm{o}}, \mathrm{V}\right)$, que, como se destaca em doutrina, não se limita ao pluralismo partidário:

Embora a Constituição brasileira, assim como tantas outras, utilize a expressão pluralismo agregando-lhe o adjetivo político, fato que à primeira vista poderia sugerir tratar-se de um princípio que se refere apenas a preferências políticas e/ou

\footnotetext{
${ }^{9}$ Ana Carolina Brochado TEIXEIRA. Saúde, corpo e autonomia privada. Rio de Janeiro: Renovar, 2010, p. 147.

${ }^{10}$ Sobre o complexo tema, v. Gisele CitTadino. Pluralismo, direito e justiça distributiva. Rio de Janeiro: Lumen Juris, 1999.
} 
ideológicas, em verdade a sua abrangência é muito maior, significando pluralismo na polis, ou seja, um direito fundamental à diferença em todos os âmbitos e expressões da convivência humana - tanto nas escolhas de natureza política quanto nas de caráter religioso, econômico, social e cultural, entre outras - um valor fundamental, portanto, cuja essência Arthur Kaufmann logrou traduzir em frase de rara felicidade: não só, mas também. Dessarte, falar em pluralismo político significa dizer que, respeitadas as poucas restrições estabelecidas na própria Lei Fundamental - pois nesse terreno é imperativa a reserva de Constituição -, o indivíduo é livre para se autodeterminar e levar a sua vida como bem lhe aprouver, imune a intromissões de terceiros, sejam elas provenientes do Estado, por tendencialmente invasor, ou mesmo de particulares. ${ }^{11}$

Da mesma forma, a expressa opção por uma república que objetiva a constituição de uma sociedade livre, justa e solidária $\left(\mathrm{CF}\right.$, art. $3^{\circ}$, I) e pela promoção do bem de todos, sem qualquer tipo de preconceito $\left(\mathrm{CF}\right.$, art. $3^{\circ}$, III), impõem, a priori, o respeito às concepções pessoais de felicidade e ao livre desenvolvimento da própria personalidade. Afinal, a pessoa pode, no âmbito de um catálogo aberto de direitos fundamentais constitucionalmente tutelado, buscar a arquitetura do seu estilo de vida, consoante os valores pessoais que a realizem. $^{12}$

É esta liberdade que franqueia a possibilidade de cada sujeito elaborar sua própria identidade, a qual, embora construída dialogicamente com seus convivas, torna-se única e individual, elemento de seu destacamento frente a seus pares. Em atendimento a este aspecto fundamental da proteção à dignidade da pessoa humana - e em reação à notória insuficiência do tradicional rol de direitos da personalidade - tornou-se comum a referência a um "direito à identidade pessoal”. Embora não protegido por dispositivo legal específico, a jurisprudência pioneiramente dele se utilizou em hipóteses nas quais o sujeito se via lesado na sua dignidade por ser retratado com caracteres identificativos incompatíveis com aqueles que escolhera para guiar sua vida pessoal e social. ${ }^{13}$ Trata-se, portanto, de mais um

\footnotetext{
${ }^{11}$ Paulo Gustavo Gomes Branco, Inocêncio Mártires CoElHo e Gilmar Ferreira MENDES. Curso de Direito Constitucional. São Paulo: Saraiva, 2007, p. 146.

${ }^{12}$ Ana Carolina Brochado TeIXEIRA. Saúde, corpo e autonomia privada. Rio de Janeiro: Renovar, 2010, p. 112-113.

${ }^{13}$ Os precedentes italianos da década de 1970 envolviam um casal cuja imagem foi utilizada em uma propaganda contrária à lei do divórcio, um tradicional político indicado como membro do partido adversário e um médico indicado como se defendesse que os cigarros seriam menos danos que o alardeado. Sobre o tema, v. Carlos Fernández SeSSAREgo, Derecho a la identidad personal, Buenos Aires: Astrea, 1992, e Giorgio PINO, Il diritto all'identità personale. Bologna: Mulino, 2003. Entre nós, o caso mais citado é o da atriz e apresentadora Xuxa Meneguel, que conseguiu impedir o lançamento em videocassete do filme 'Amor, estranho amor', película de cunho erótico exibida no cinema cuja difusão deturparia sua imagem junto ao público infantil. O TJRJ entendeu que: "após o lançamento da fita (no cinema), ocorrido em 1982, Xuxa se projetou, nacional e internacionalmente, com programas infantis na televisão, criando uma imagem que muito justamente não quer ver atingida, cuja vulgarização atingiria não só ela própria como as crianças que são o
} 
instrumento jurídico para garantir o respeito às escolhas de vida individuais de caráter existencial, cerne da tutela conferida à dignidade da pessoa humana.

Entretanto, sem sombra de dúvida, o instrumento jurídico que mais nitidamente acolhe este movimento de respeito à esfera de livre escolha existencial é o direito à privacidade. Tradicionalmente entendida, a partir da difusão de Warren e Brandeis da visão de Robert Kerr, como "o direito a ficar só”, a privacidade sofreu drástica transformação e ampliação nas últimas décadas, impelida pelas inovações tecnológicas e pela extensão da proteção às situações jurídicas existenciais. As críticas à concepção do indivíduo murado, isolado, em que se baseava a concepção tradicional, e da tutela puramente negativa, de exclusão, a que ela dava origem, deram lugar ao entendimento da privacidade como "o direito à autodeterminação informativa", consistente no real poder sobre nossas próprias informações. ${ }^{14}$ Resguarda-se, assim, o sujeito contra o acesso e a interferência aos seus dados pessoais, em especial aqueles ditos "sensíveis", relativos às suas escolhas mais individuais, como sentimentos, conduta sexual, saúde, defeitos físicos, fé religiosa, idéias políticas.

A partir desta reformulação, a tutela da privacidade, prevista expressamente entre nós nos arts. $5^{\circ}, \mathrm{X}$, da Constituição, e 21 do Código Civil, vem sendo defendida como uma cláusula geral de tutela da autodeterminação quanto às escolhas existenciais, entendida "a 'inviolabilidade da vida privada' não como a tímida tutela do microcosmo da casa, mas como o espaço (inviolável) da liberdade de escolhas existenciais". ${ }^{15}$

Assim, enquanto as relações patrimoniais são mero instrumento, a ser funcionalizado a outros valores constitucionais e, portanto, esferas em que a autonomia é merecedora de tutela de forma condicionada, nas relações existenciais a liberdade parte com prioridade para realização da dignidade, a ser sopesada somente em situações

seu público, ao qual se apresenta como símbolo da liberdade infantil, de bons hábitos e costumes, e da responsabilidade das pessoas" (TJRJ, $2^{\mathrm{a}}$ Câmara Cível, Apelação Cível 1991.001.03819, Des. Thiago Ribas Filho, julg. 27.02.1992). V. Raul Cleber da Silva CHOERI. O direito à identidade na perspectiva civilconstitucional. Rio de Janeiro: Renovar, 2010.

${ }^{14}$ Stefano Rodotà. A vida na sociedade de vigilância: privacidade hoje. Rio de Janeiro: Renovar, 2008. Entre nós, v. Danilo DonedA. Da privacidade à proteção de dados pessoais. Rio de Janeiro: Renovar, 2006; e Bruno LEWICKI. A privacidade da pessoa humana no ambiente de trabalho. Rio de Janeiro: Renovar, 2003.

${ }^{15}$ Maria Celina Bodin de MoRAEs. Ampliando os direitos da personalidade. Na medida da pessoa humana. Rio de Janeiro: Renovar, 2010, p. 148. 
excepcionais, que envolvam desrespeito à solidariedade ou outros aspectos igualmente prioritários à própria dignidade.

Nestes termos, a proteção à livre realização de um projeto de existência individual deve ser um dos maiores objetivos de um ordenamento jurídico que preza pela tutela da pessoa humana, pois significa que sua dignidade está sendo realizada, uma vez que a personalidade está sendo construída da forma que o próprio indivíduo escolheu para si. Sendo a dignidade um dos escopos da República Federativa do Brasil e o pluralismo um dos pilares do Estado Democrático de Direito, não há outra forma que não esta de deixar que a pessoa construa seu próprio caminho, sua própria identidade. Por isso, é defeso ao Estado, ao legislador, ou governo, a outras pessoas interferirem na edificação e na concretização desse projeto de vida individual, pois faz parte das escolhas mais íntimas que cada um faz para si. Esse núcleo está submetido apenas ao exercício da própria autonomia.

Deve a Constituição garantir que esse espaço de autonomia seja preservado, sob pena de supressão da subjetividade. É preciso que, efetivamente, abram-se os espaços para que as escolhas individuais possam ser feitas e para que cada pessoa possa participar da construção da sua personalidade e dignidade. Foi dessa forma que o constituinte traçou as diretrizes da abertura do catálogo de direitos fundamentais. Trata-se de possibilidades atribuídas a cada indivíduo, para que ele escolha a melhor forma de se realizar, através dos aspectos pessoais que lhe franqueia a autonomia privada. Nesse sentido, no âmbito dos direitos fundamentais, pode a pessoa agir de acordo com o entender seja melhor para si, principalmente no que tange às decisões referentes a si, ao seu corpo, à sua individualidade. Em questões de maior intimidade, portanto, o fio norteador deve ser a autonomia privada, pois a vontade individual é a mais legítima a guiar tais decisões, em lugar da imposição do Estado ou de terceiros. Conforme afirma Stefano Rodotà, trata-se de um espaço "indecidibile per il legislatore", ou seja, um espaço no qual a decisão da pessoa é a verdadeiramente legítima, quando estiver em jogo questões afetas à sua personalidade. É um espaço delimitado pelo constituinte e, dentro desse limite, o Estado autorizou a ação do particular:

Relega-se assim o coração do problema, que consiste justamente em uma avaliação preventiva quanto ao "se" da decisão, quanto à própria conveniência de legislar em situações em que a consciência a respeitar não é a dos deputados e senadores, mas a das mulheres e homens que devem poder governar a sua própria existência. E que, portanto, não devem ser expropriados da liberdade de decisão, mas sim colocados em posição de exercê-la responsavelmente, da mesma forma 
que os doutos, para os quais "não se trata de apelar à fé ou à religião, mas de confiar em uma tomada de consciência" (Ignazio Marino). A democracia é também sobriedade e respeito. ${ }^{16}$

E complementa o autor:

A lei não pode, em nenhum caso, violar os limites impostos pelo respeito à pessoa humana, diz com sua bela linguagem a Constituição [italiana] no seu artigo 32. É a consciência individual, com os seus tormentos, que deve ser respeitada por um legislador ao qual se destina a sobriedade e, nos casos limites, o silêncio. Ademais, concordando que exista uma área "indecidível” para o legislador e remetida às decisões individuais, no quadro de princípios gerais se encontraria uma regra capaz de evitar conflitos lacerantes onde se invoquem valores considerados inegociáveis."17

Assim, utilizando a construção que já se tornou referência, a proteção à dignidade da pessoa humana tem por corolários a tutela da integridade psicofísica, da igualdade, da liberdade e da solidariedade. ${ }^{18}$ Nesta difícil ponderação entre liberdade e solidariedade se encontra o desafio de reconstruir, sob este novo paradigma, o conceito de autonomia privada. O problema da disposição de órgãos para depois da morte constitui exemplo da

16 Tradução livre de Stefano RoDOTÀ. Politici, liberateci dalla vostra coscienza. Disponível em <http://daleggere.wordpress.com/2008/01/13/stefano-rodota-\%C2\%ABpolitici-liberateci-dalla-vostracoscienza\%C2\%BB/>, acesso em 14 jul. 2008. No original: "Si trascura così il cuore del problema, che consiste appunto in una valutazione preventiva intorno al "se" della decisione, all'opportunità stessa del legiferare quando la coscienza da rispettare non è quella di deputati e senatori, ma quella delle donne e degli uomini che devono poter governare la loro esistenza. E che, quindi, non devono essere espropriati della libertà di decisione, ma messi in grado di esercitarla responsabilmente, allo stesso modo degli scienziati, per i quali «non si tratta di appellarsi alla fede o alla religione ma di puntare su una presa di coscienza» (così Ignazio Marino). La democrazia è anche sobrietà e rispetto.". Neste sentido, afirma ainda Rodotà: "Per carità, la libertà di coscienza va sempre presa in considerazione. Ma in realtà in queste materie cosiddette eticamente sensibili e che riguardano decisioni individuali, la libertà di coscienza che deve essere rispettata è quella della persona che deve prendere la decisione. Il punto chiave non è la libertà di coscienza del politico ma il fatto che la legge non può espropriare la libertà di coscienza di ciascuno di noi. E questo è un limite all'invasività della politica e all'uso proibizionista della legge. Inoltre è anche evidente che così la politica perde il suo senso di grande dibattito pubblico e si privatizza, e anche questo è sintomo della regressione culturale. Il confronto tra le idee lascia il posto all'arroccamento sulla torre d'avorio della propria coscienza, della quale non si risponde né alla politica né alla collettività. Ma attenzione all'effetto cascata delle obiezioni di coscienza: perché allora un giudice non potrebbe rifiutarsi di applicare una legge non conforme alla propria coscienza?"

17 Tradução livre de Stefano RoDOTÀ. Politici, liberateci dalla vostra coscienza. Disponível em <http://daleggere.wordpress.com/2008/01/13/stefano-rodota-\%C2\%ABpolitici-liberateci-dalla-vostra-

coscienza\%C2\%BB/>, acesso em 14 jul. 2008. No original, "La legge non può in nessun caso violare i limiti imposti dal rispetto della persona umana', dice con il suo bel linguaggio la Costituzione proprio nell'articolo 32. É la coscienza individuale, con $i$ suoi tormenti, a dover essere rispettata da un legislatore al quale si addice la sobrietà e, nei casi limite, il silenzio. Inoltre, convenendo che vi sia un'area 'indecidibile' per il legislatore e rimessa alle decisioni individuali nel quadro di principi generali, si troverebbe una regola capace di evitare conflitti laceranti là dove una o più delle parti politiche faccia riferimento a valori ritenuti non negoziabili. [...]".

${ }^{18}$ Maria Celina Bodin de MoRAES. Danos à pessoa humana. Rio de Janeiro: Renovar, 2003, p. 201 e ss. 
importância do esforço em repensar o conteúdo, as fronteiras e, principalmente, a função da autonomia privada em um sistema guiado pela proteção da dignidade da pessoa humana.

\section{Transformações na legislação dos transplantes}

Toda legislação de transplantes de órgãos e tecidos está calcada em uma ponderação entre liberdade e solidariedade. De um lado, a liberdade de decidir acerca do destino de seu corpo, mesmo depois da morte, respeitando convicções religiosas ou pessoais. De outro lado, a solidariedade presente na possibilidade, oferecida pela ciência médica, de que o material biológico já não mais útil ao seu portador original possa servir para garantir a saúde ou mesmo a sobrevivência de outra pessoa - a "preservação da vida de alguém por meio do uso de órgãos de outras pessoas". ${ }^{19}$ No problema em exame, verificamos ainda a colisão entre os interesses manifestados em vida do eventual doador, falecido, e os interesses dos familiares vivos - nos termos da lei, "cônjuge ou parente, maior de idade, obedecida a linha sucessória, reta ou colateral, até o segundo grau inclusive" - no tocante ao destino do corpo do ente querido falecido.

No Brasil, a legislação sobre os transplantes se inicia com a Lei n. 4.280, de 6 de novembro de 1963, mas foi com a Lei n. 5.479, de 10 de agosto de 1968, que se passou a exigir com destaque que o transplante só ocorresse com expressa manifestação de vontade do disponente ou de familiar. ${ }^{20}$ No sistema original, portanto, o sopesamento era feito de forma que somente na ausência de opção expressa do titular no sentido da doação, e ainda da família, não ocorreria o transplante, mas bastava que um ou outro autorizasse a doação para que ela fosse viabilizada.

Com o desenvolvimento da tecnologia médica e o crescimento da demanda pelos transplantes, a normativa foi substituída no início da década de noventa, já com uma sutil

\footnotetext{
${ }^{19}$ Giselda Maria Fernandes Novaes HIRONAKA. Bioética e biodireito: revolução biotecnológica, perplexidade humana e prospectiva jurídica inquietante. Revista brasileira de direito de família, v. 16, jan.-mar./2003, p. 48. Sobre o papel da solidariedade e do altruísmo na política de transplantes, v. José Roque Junges. Bioética: perspectivas e desafios. São Leopoldo: Unisinos, 1999, pp. 205 e ss.

${ }^{20}$ L. $5.479 / 68$, art. $3^{\circ}$ : "A permissão para o aproveitamento, referida no art. $1^{\circ}$, efetivar-se-á mediante a satisfação de uma das seguintes condições: I - Por manifestação expressa da vontade do disponente; II - Pela manifestação da vontade, através de instrumento público, quando se tratar de dispoentes relativamente incapazes e de analfabetos; III - Pela autorização escrita do cônjuge, não separado, e sucessivamente, de descendentes, ascendentes e colaterais, ou das corporações religiosas ou civis responsáveis pelo destino dos despojos; IV - Na falta de responsáveis pelo cadáver a retirada, somente poderá ser feita com a autorização do Diretor da Instituição onde ocorrer o óbito, sendo ainda necessária esta autorização nas condições dos itens anteriores".
} 
alteração no sentido da solidariedade: de acordo com a Lei n. 8.489, de 18 de novembro de 1992, no silêncio do possível doador, somente a recusa expressa da família impediria a doação - presumia-se seu consentimento. ${ }^{21}$ Como destacou na ocasião José Carlos Moreira Alves, criticando a forma pela qual a lei foi regulamentada: "o que se deveria dar ao cônjuge, ao ascendente ou ao descendente era a oportunidade de opor-se, se assim o quisesse, caso em que a iniciativa partiria dele, implicando o silêncio sua não-oposição, o que é diverso da necessidade de autorização por escrito que, em última análise, representou a volta - da legalidade discutível - ao sistema da legislação anterior". ${ }^{22}$

Mas foi com a criação do Sistema Nacional de Transplantes, em 1997, que se instituiu verdadeira reviravolta: além da constituição de mecanismos mais transparentes e eficazes, buscava-se reduzir a escassez de órgãos para doação, tendo por base o princípio de solidariedade social. ${ }^{23}$ Para a doação post-mortem, a Lei n. 9.434, de 4 de fevereiro de 1997, dava o passo pioneiro de introduzir a presunção de consentimento, salvo prévia manifestação de vontade em sentido contrário. ${ }^{24}$ Instituía-se no Brasil, de forma precursora, o chamado opting out system, em lugar do generalizado sistema de informação aos parentes. ${ }^{25}$ Aqueles que não desejassem ser doadores deveriam fazer constar da carteira de identidade ou de motorista e, como estas passariam a ser emitidas obrigatoriamente com esta declaração, a norma de consulta subsidiária aos familiares teria sua aplicação cada vez mais reduzida, vindo o sistema a converter-se no de declaração obrigatória.

\footnotetext{
${ }^{21}$ L. 8.489/92, art. $3^{\text {o: }}$ "Art. $3^{\circ}$ A permissão para o aproveitamento, para os fins determinados no art. $1^{\circ}$ desta lei, efetivar-se-á mediante a satisfação das seguintes condições: I - por desejo expresso do disponente manifestado em vida, através de documento pessoal ou oficial; II - na ausência do documento referido no inciso I deste artigo, a retirada de órgãos será procedida se não houver manifestação em contrário por parte do cônjuge, ascendente ou descendente". Como destacou na ocasião José Carlos Moreira Alves, "o que se deveria dar ao cônjuge, ao ascendente ou ao descendente era a oportunidade de opor-se, se assim o quisesse, caso em que a iniciativa partiria dele, implicando o silêncio sua não-oposição, o que é diverso da necessidade de autorização por escrito que, em última análise, representou a volta - da legalidade discutível - ao sistema da legislação anterior"

${ }^{22}$ José Carlos Moreira ALVES. Os aspectos jurídicos, éticos e legais dos transplantes de órgãos. Revista de Direito Renovar, n. 1, jan./abr. de 1995, p. 9.

${ }^{23}$ Ainda sobre o projeto, afirmava Antonio ChAVEs: "O que importa assinalar é o critério verdadeiramente inovador que trazia o projeto de lei do governo de substituir a indispensabilidade de consentimento expresso do disponente em vida, só possível de alguns raros doadores esclarecidos que consigam vencer sua própria inércia, ou de seus parentes mais próximos, em geral tomados de escrúpulos, pelo aproveitamento, ressalvada a manifestação prévia em sentido contrário" (Direito à vida e ao próprio corpo: intersexualidade, transexualidade, transplantes. São Paulo: Revista dos Tribunais, 1994, p. 253).

${ }^{24}$ Redação original do art. $4^{\circ}$ : "Salvo manifestação de vontade em contrário, nos termos desta Lei, presume-se autorizada a doação de tecidos, órgãos ou partes do corpo humano, para finalidade de transplantes ou terapêutica post mortem".

${ }^{25}$ Sobre os sistemas, v. Maria Helena DinIZ. O estado atual do biodireito. São Paulo: Saraiva, 2001, p. 271.
} 
A radical transformação, todavia, gerou intensa polêmica, causando grande mobilização na mídia e na sociedade civil de modo geral. Seus opositores alegavam que a lei era inconstitucional "pela estatização do corpo humano, devido ao fato de o Estado ficar com algo que não é seu", desrespeitando "o direito individual da pessoa à sua integridade física e dignidade" e o "princípio filosófico do controle do homem sobre o próprio corpo". ${ }^{26}$ Além desta linha de argumentação fundada na afronta à autodeterminação e na interferência exagerada na esfera privada, vinculada à tradição liberal, invocou-se também a falta de informação da população brasileira como fator impeditivo para uma manifestação plenamente consciente de vontade. ${ }^{27}$

Estes argumentos, aliados a certa desconfiança com relação ao critério de avaliação da morte encefálica - e com relação ao rigor de sua aferição diante da ameaça do tráfico de órgãos ${ }^{28}$ - geraram pressão suficiente para fazer com que o executivo editasse uma medida provisória retornando ao sistema anterior: de acordo com a MP 1.718, de 6 de outubro de 1998, na ausência de manifestação expressa de vontade do doador, os familiares poderiam impedir a realização do transplante. ${ }^{29}$

No entanto, depois de reeditada 26 vezes, a medida provisória foi sub-repticiamente alterada, revertendo completamente o avanço legislativo inicial e exigindo sempre o consentimento expresso dos familiares, independentemente da opção declarada pelo doador: na redação dada pela MP 1.959-27, de 24 de outubro de 2000, “a retirada de tecidos, órgãos e partes do corpo de pessoas falecidas para transplantes ou outra finalidade terapêutica dependerá da autorização do cônjuge ou parente, maior de idade, obedecida a

\footnotetext{
${ }^{26}$ É o que relata Maria Helena DinIZ. O estado atual do biodireito, cit., p. 289.

${ }^{27}$ Para uma análise dos argumentos, v. Rodrigo Pessoa Pereira da SILVA. Doação de órgãos: uma análise dos aspectos legais e sociais. In: Maria de Fátima Freire de SÁ (coord.). Biodireito. Belo Horizonte: Del Rey, 2002, pp. 419-424. A ementa a seguir também retrata bem a concepção então vigente, não obstante se trate de consentimento de menor que não poderia ser colhido, para se manifestar sobre sua condição ou não de doador de órgãos: "AÇÃO CIVIL PÚBLICA. Lei no 9434/97. Remoção de órgãos, tecidos e partes do corpo humano para fins de transplante e tratamento. Doação. Gravação da expressão "não doador de órgãos e tecidos", na Carteira de Identidade Civil. Menor de dezoito anos. Exigência indevida de manifestação de vontade do menor pelo Instituto de Identificação através de representação ou assistência. Impossibilidade jurídica, para efeitos da lei em comento, vez que, para a disposição "post mortem" de tecidos, órgãos e partes do corpo humano, não têm os representantes ou os assistentes poderes legais para suprir a incapacidade. Manutenção da sentença." (TJMG, Ap. Cív. 167.579-2/00, 2ª . CC, Rel. Pinheiro Lago, J. 19/12/2000, DJMG 16/2/2001)

${ }^{28}$ Sobre o tema, v. Giovanni Berlinguer e Volnei GARRAFA. O mercado humano: estudo bioético da compra e venda de partes do corpo Brasília: UnB, 1996.

${ }^{29}$ A MP incluiu um novo parágrafo ao art. $4^{\circ}$ : "§ $6^{\circ}$. Na ausência de manifestação de vontade do potencial doador, o pai, a mãe, o filho ou o cônjuge poderá manifestar-se contrariamente à doação, o que será obrigatoriamente acatado pelas equipes de transplante e remoção".
} 
linha sucessória, reta ou colateral, até o segundo grau, inclusive, firmada em documento subscrito por duas testemunhas presentes à verificação da morte”. Esta medida provisória veio a se converter, depois de mais cinco reedições, na Lei n. 10.211, de 23 de março de $2001 .^{30}$

A legislação especial sobre o tema, portanto, na ponderação entre liberdade e solidariedade, prioriza a liberdade, mas, curiosamente, não a liberdade do possível doador e sim a liberdade da família. De fato, entre as duas, a liberdade do possível doador é absolutamente desprezada diante do desejo da família: ainda que o falecido tenha, em um gesto de solidariedade, exprimido o desejo de doar seus órgãos, esta manifestação será desconsiderada se a família não concordar expressamente com o transplante.

\section{O Código Civil e as disposições para depois da morte}

O cenário apresentado pela legislação especial a partir de 2000 foi, todavia, problematizado por um dispositivo do Código Civil de 2002. O Código, justificadamente, recebeu inúmeras críticas por nascer envelhecido, sem levar em conta a história constitucional e a experiência jurisprudencial brasileira, em especial no tocante ao seu capítulo de direitos da personalidade. ${ }^{31}$ Mas curiosamente é exatamente neste capítulo que encontramos um enunciado normativo que se contrapõe à linha adotada pela legislação especial. Talvez seja um influxo da referida "lógica da socialidade" que guiou o projeto, inspirada exatamente na solidariedade constitucional, ou talvez simplesmente porque mesmo a posição assumida pela lei de transplantes atual seja ainda mais antiquada que o espírito da década de 70 que permeou a redação do Código Civil.

A referida "novidade" é o artigo 14, que determina que "é válida, com objetivo científico, ou altruístico, a disposição gratuita do próprio corpo, no todo ou em parte, para

\footnotetext{
${ }^{30} \mathrm{O}$ parágrafo único originalmente previsto no projeto ("A retirada de tecidos, órgãos e partes do corpo de pessoas falecidas poderá ser realizada a partir de registro feito em vida, pelo de cujus, nos termos do regulamento") foi vetado pelo executivo por poder conduzir a interpretação diversa. A nova lei também invalidou as declarações existentes: "art. $2^{\circ}$. As manifestações de vontade relativas à retirada 'post mortem' de tecidos, órgãos e partes, constantes da Carteira de Identidade Civil e da Carteira Nacional de Habilitação, perdem sua validade a partir de 22 de dezembro de 2000 ".

${ }^{31} \mathrm{Na}$ a lição de Gustavo TEPEDINO: "o novo Código nascerá velho principalmente por não levar em conta a história constitucional brasileira e a corajosa experiência jurisprudencial, que protegem a personalidade humana mais do que a propriedade, o ser mais do que o ter, os valores existenciais mais do que os patrimoniais. E é demagógico porque, engenheiro de obras feitas, pretende consagrar direitos que, na verdade, estão tutelados em nossa cultura jurídica pelo menos desde o pacto político de outubro de 1988" (O Novo Código Civil: duro golpe na recente experiência constitucional brasileira. Temas de Direito Civil, t. II. Rio de Janeiro: Renovar, 2004, p. 358).
} 
depois da morte". ${ }^{32}$ Enquanto o dispositivo precedente, referente aos atos de disposição em vida, remeta para a legislação especial ( $\mathrm{CC}$, art. 13, parágrafo único), no tocante à disposição do corpo para depois da morte, com fim científico ou altruístico, o Código assegura, de forma assertiva, a sua validade. A ratio do dispositivo é clara: a proteção do desejo do falecido, neste caso, é, simultaneamente, a tutela da liberdade, pois assegura a disposição do corpo, e da solidariedade, pois atende à finalidade científica ou altruísta.

A antinomia se estabelece, portanto, entre o art. $4^{\circ}$ da Lei de Transplantes (L. 9.434/97, alterada pela L. 10.211/01), que determina que a legitimidade para autorizar a retirada de partes do corpo depois da morte para fins de transplante é da família, desconsiderada assim a declaração do falecido, e o art. 14 do Código Civil de 2002, que prevê a validade da declaração feita pelo falecido no sentido da disposição de seus órgãos com finalidade altruística ou científica.

Pela utilização dos critérios tradicionais de solução de conflitos entre regras, a norma especial prevalece sobre a norma geral, todavia a norma geral, neste caso, é posterior. ${ }^{33}$ Mas especialmente em uma antinomia como esta, envolvendo a tutela da liberdade e da solidariedade - e, portanto, da dignidade humana - é imperioso solucionar o conflito a partir da tábua de princípios constitucionais que inspira e imanta todo o sistema. Como leciona Pietro Perlingieri: “a norma não está nunca sozinha, mas existe e exerce sua função no interior do ordenamento, e o seu significado muda com o dinamismo e a complexidade do próprio ordenamento". 34

Entretanto, deve-se ter em mente que o conflito aqui não é simplesmente entre liberdade e solidariedade, como de costume, mas sim entre a liberdade do possível doador (amparada também pela solidariedade) e o interesse da família. ${ }^{35}$ O que se cogita é o

\footnotetext{
${ }^{32}$ O parágrafo único do dispositivo assegura a revogabilidade da disposição: “Art. 14. [...] Parágrafo único. O ato de disposição pode ser livremente revogado a qualquer tempo".

${ }^{33}$ Para uma apresentação dos critérios clássicos de solução de antinomias, v., entre todos, Norberto BoBBIO. Teoria do ordenamento jurídico, 10. ed. Brasília: UNB, 1997.

${ }^{34}$ Pietro PERLINGIERI. Il diritto civile nella legalità costituzionale, t. II, 3. ed. Napoli: ESI, 2006, p. 580.

${ }^{35} \mathrm{O}$ interesse da família é descrito por Maria de Fátima Freire de SÁ: "Porém, sabe-se, não é por já não terem vida, nem porque não mais se prestam a ela, que os mortos deixam de ser importantes para as suas famílias. Ao contrário. Talvez estas fiquem muito mais apegadas, naquele momento de dor, conscientes de que seus entes queridos continuam a traduzir a imagem da pessoa viva, e o que é mais desesperador, tal como uma imagem congelada, um retrato que não se expressa - não fala, não sente, mas projeta a pessoa querida, de forma com que ela faça parte da sua convivência e do seu dia-a-dia, muitas vezes como um 'pano de fundo', dependendo do grau de afetividade que as ligava ao falecido" (Biodireito e direito ao próprio corpo. Belo Horizonte: Del Rey, 2000, p. 74).
} 
sacrifício de um desejo individual do falecido - que em vida seria plenamente amparado pelo direito - em nome do desejo de seus familiares ainda vivos. Para realizar esta ponderação, portanto, é necessário abordar qual o papel e a importância da família na ordem constitucional contemporânea.

\section{A funcionalização da família e o respeito à decisão do doador}

A estrutura imposta pela legislação especial sobre transplantes para a doação de órgãos post mortem, determinando que prevaleça sempre a vontade dos familiares, é típica do modelo tradicional de tutela jurídica da família. Neste modelo, a chamada "famíliainstituição" era reputada um bem a ser protegido por si só, de forma autônoma, intocável pelo direito: qualquer intervenção estatal era vista com certa hostilidade. Em razão disso, seria tolerável - e por vezes mesmo esperado - eventual sacrifício a ser sofrido por cada um de seus componentes em nome da preservação da "célula mater" da sociedade. ${ }^{36}$

No contexto atual, todavia, a Constituição elege como princípio fundamental a dignidade da pessoa, não a intangibilidade da entidade familiar. A família, "base da sociedade", só recebe proteção especial do Estado porque é um lócus especialmente apto para garantir uma rede de amparo afetivo e material a cada um dos seus membros - e só será protegida enquanto estiver desempenhando esta função. Ela é tutelada em nome de cada um de seus integrantes, como "caminho da realização de seu projeto de felicidade pessoal". 37

Por conta disso se fala, sob a perspectiva da constitucionalização do direito civil, de "funcionalização" ou "instrumentalização" da família: as entidades familiares deixam de ser instituições protegidas em si mesmas para servirem como instrumentos para o desenvolvimento da personalidade de seus membros. Antes, a proteção da paz doméstica, da coesão formal do grupo familiar e da integridade do vínculo conjugal era considerada merecedora em si de tutela, ainda que em detrimento da realização pessoal dos seus integrantes, porque se partia da análise exclusivamente estrutural dos institutos. ${ }^{38}$ Hoje, a ratio da proteção da família é o livre desenvolvimento da personalidade de seus membros, a efetivação da dignidade de cada um de seus componentes, logo somente enquanto estiver a

\footnotetext{
${ }^{36}$ Gustavo TePedinO. Temas de direito civil, cit., p. 418.

37 Giselda Maria Fernandes Novaes HiRonAKA. Família e casamento em evolução. Revista Brasileira de Direito de Família, n. 1, abr./jun. 1999, p. 8.

${ }^{38}$ Gustavo TePeDINO. Temas de direito civil, cit., p. 372.
} 
desempenhar este papel serão as decisões da entidade familiar merecedoras de respaldo jurídico.

O modelo compatível com a ordem constitucional, então, é a "família democrática", na qual todos os membros têm voz e participação: ela é calcada no diálogo e no respeito mútuo, sem qualquer forma de violência, e nela é garantida a igualdade entre os membros e a liberdade de cada um deles sem sacrifício da solidariedade que os interliga. ${ }^{39} \mathrm{Nas}$ palavras de Anthony Giddens, “a família está se tornando democratizada, conforme modos que acompanham processos de democracia pública; e tal democratização sugere que a vida familiar poderia combinar escolha individual e solidariedade social". ${ }^{40}$ Tanto é que, cada dia mais, os membros da família vêm ganhando autonomia, com a diminuição crescente da intervenção do Estado, para que a própria família possa dirigir seus rumos. ${ }^{41}$

Neste modelo, portanto, a entidade familiar é construída no esforço de conciliar a solidariedade familiar, demandada especialmente pelos projetos comuns, com a necessária liberdade individual. ${ }^{42}$ A família, assim, é sempre suporte - e jamais obstáculo - ao desenvolvimento da personalidade de seus membros. Mesmo entre os incapazes, a quem as regras tradicionais de direito civil vedam - em nome de sua proteção - a liberdade para realizar os atos da vida civil por conta própria se vem reconhecendo autonomia na medida de sua maturidade, de modo a relativizar o regime tradicional das incapacidades. ${ }^{43}$

As relações familiares são permeadas por deveres mútuos, seja de assistência, o que se constata através dos alimentos, seja de cuidados pessoais e patrimoniais, conforme se pode extrair dos institutos da tutela, curatela, poder familiar. O art. 229 da Constituição Federal demonstra exatamente o quão intensa é a incidência do princípio da solidariedade no âmbito da família. Aos pais incumbe o cuidado com os filhos na infância e juventude,

\footnotetext{
${ }^{39}$ Maria Celina Bodin de MoRAES. A família democrática. In: Anais do V Congresso Brasileiro de Direito de Família. São Paulo: IOB Thompson, IBDFAM, 2006, p. 613-640

${ }^{40}$ Anthony GidDEns. A Terceira Via: Reflexões sobre o Impasse Político Atual e o Futuro da SocialDemocracia, Rio de Janeiro: Record, 2000 p. 98, apud Maria Celina Bodin de MoRAES. A família democrática, cit., p. 616.

${ }^{41}$ Demonstrações dessa afirmação não faltam: a Lei 11.447/2007 - que autorizou o procedimento cartorial da separação e o divórcio - e a recente aprovação da Emenda Constitucional 66, que aboliu a necessidade da discussão de tempo para a dissolução do casamento, expurgou a culpa do Direito de Família matrimonial e, segundo a doutrina majoritária, pôs fim ao instituto da separação (judicial e extrajudicial).

${ }^{42}$ Ana Carolina Brochado TeIXEIRA. Família, guarda e autoridade parental. Rio de Janeiro: Renovar, 2009, p. 29.

${ }^{43}$ Sobre o tema, v.. Ana Carolina Brochado TeIXeIRA et. al.. Autonomia privada da criança e do adolescente: uma reflexão sobre o regime das incapacidades. Revista Brasileira de Direito das Famílias e Sucessões, v. 1, 2007, pp. 57-73.
} 
quando ainda não têm maturidade, o que justifica a existência de um processo educacional; aos filhos é atribuído o dever de cuidado dos pais na velhice, carência ou doença, isto é, quando necessitarem de assistência. ${ }^{44}$

Isso não significa a não incidência do princípio da autonomia privada no âmbito da família. Se a família passou a ser instrumento para a livre realização dos seus membros, sua formação e manutenção apenas se justifica enquanto significar uma escolha, no que tange à conjugalidade. Logo, o que origina a formação familiar é exatamente um ato de liberdade; contudo, após sua constituição, há forte incidência de deveres mútuos, cuja gênese é o princípio da solidariedade, principalmente enquanto algum de seus membros tiver alguma vulnerabilidade. Vulnerabilidade justifica diminuição de autonomia, pois uma das condições para se ter plena autonomia é a ampla capacidade do sujeito, que pressupõe a vontade livre, em todos os sentidos, para que possa praticar, validamente, atos jurídicos. A vulnerabilidade é razão justificadora da publicização de algumas relações, pois, neste caso, a autonomia das partes pode não ser suficiente para assegurar a concretização da dignidade, uma vez que ambas não são detentoras de iguais liberdades. ${ }^{45}$

Constata-se, portanto, o constante conflito entre liberdade e solidariedade: a liberdade na formação da família, da forma de realização no interior da família e, simultaneamente, a intensa incidência do princípio da solidariedade, pois, na relação afetiva com "o outro", no âmbito da alteridade familiar, existe corresponsabilidade. Como justificar, então, que, depois da morte, não prevaleça mais a decisão tomada pela pessoa, porque incompatível com o desejo de seus familiares?

Não ampara este entendimento o fato de a extinção da personalidade com a morte conferir legitimidade aos familiares para zelarem, a partir de então, pelos aspectos da personalidade do de cujus (CC, art. 12, parágrafo único, e art. 20, parágrafo único).

\footnotetext{
44 "No direito moderno, a propriedade, posto que individual, é como que assegurada aos membros do grupo familiar, não é porque a todos pertença em comum, mas em razão do princípio da solidariedade, que fundamenta deveres de assistência do pai aos filhos, e por extensão a outros membros da família, bem como do filho ao pai, por força do que dispõe o art. 229 da Constituição de 1988. Visa, então, a transmissão hereditária a proporcionar originariamente aos descendentes a propriedade do antecessor, segundo o princípio da afeição real ou presumida, que respectivamente informa a sucessão legítima e a testamentária." (Caio Mário da Silva PereIRA. Instituições de direito civil, vol. VI, 15. ed., atualizada por José Carlos BARBOSA MOREIRA. Rio de Janeiro: Forense, 2004, p. 6-7)

45 Sobre vulnerabilidade no âmbito da família, recomendamos Maria Celina BodIN DE MORAES. Vulnerabilidades nas relações de família: o problema da desigualdade de gênero. In: Maria Berenice Dias. (Org.). Direito das famílias. Contributo do IBDFAM em homenagem a Rodrigo da Cunha Pereira. São Paulo: Revista dos Tribunais, 2009, p. 306-322.
} 
Primeiro, porque, do ponto de vista técnico, ao lado destes dispositivos, o mesmo diploma prevê, em dispositivo específico, a validade das disposições post mortem com fim altruístico ou científico (o referido art. 14). Portanto, os referidos artigos somente seriam aplicáveis na ausência de expressa manifestação de vontade do falecido.

Segundo porque a ponderação que subjaz a estes dispositivos não autoriza que a vontade dos familiares prevaleça sobre a vontade do titular manifestada ainda em vida. De fato, a estrutura jurídica desta legitimação é objeto de grande controvérsia, com explicações que vão desde uma personalidade residual do defunto até o reconhecimento dos direitos das pessoas vivas afetadas, passando inclusive pela sustentação de uma espécie de fidúcia ou curadoria dos bens existenciais do falecido. ${ }^{46}$ Do ponto de vista funcional, todavia, há que se reconhecer que depois da morte ainda há interesses existenciais merecedores de tutela e que se atribui aos familiares, como em princípio mais vinculados ao morto, a legitimidade para defendê-los e a terceiros, o dever de respeitar o morto, bem como sua imagem, privacidade, honra e nome. Trata-se de uma atribuição residual, subsidiária, diante de uma lesão que pode ser tanto à dignidade do falecido como, indiretamente, de modo reflexo, à própria família. $^{47}$

Neste sentido, a melhor doutrina defende que os familiares em tais casos estariam na verdade investidos de um poder-dever, a ser exercido no presumido interesse da pessoa falecida: “apesar de não existir propriamente uma obrigatoriedade de ação, há, por outro lado, um poder de controle quanto à tutela da personalidade da pessoa falecida, que poderá ser exercido pelos próprios titulares do poder-dever em relação à ação de seus pares". ${ }^{4}$

Logo, diante da possibilidade de a própria pessoa se autodeterminar e de haver uma heterodeterminação - mesmo que por membros da família, os quais, presumidamente, são caros à pessoa - em questões existenciais, as diretrizes constitucionais são sempre no sentido de preservar a vontade da pessoa, desde que exteriorizada através de uma decisão

\footnotetext{
${ }^{46}$ Rabindranath Valentino Aleixo Capelo de SousA. O Direito geral de personalidade. Coimbra: Coimbra Editora, 1995, pp. 401 e ss.

${ }^{47}$ Como explica Pietro PERLINGIERI: "Si discute se i familiari piú stretti del defunto abbiano un proprio interesse a far valere la di lui dignitià ed onorabilità oppure se essi abbiano la sola legittimazione a proporre l'azione (in quanto l'interesse permarrebbe in capo al congiunto anche dopo la sua morte). Il rilievo che la lesione alla dignitià della famiglia e dei suoi singoli componenti induce a concludere che il congiunto agisce quale titolare di un interesse, ad un tempo personale e familiare, che affonda le sue radici non soltanto in un diritto, ma anche in un dovere di solidarietà familiare" (Manuale di diritto civile, 4. ed. Napoli: ESI, 2005, p. 150)

${ }^{48}$ Ana Luiza Maia Nevares. A função promocional do testamento. Rio de Janeiro: Renovar, 2009, p. 129.
} 
autônoma e responsável, mesmo que ela venha a produzir efeitos após a sua morte. Mesmo porque, se assim não fosse, o testamento e o consentimento autorizado pelo Código Civil e pela lei de doação de doação de órgãos cairiam no vazio, não sendo um exemplo de garantia de autonomia prospectiva dada pelo próprio ordenamento jurídico.

\section{A questão sucessória: liberdade de testar plena ou mitigada?}

O direito das sucessões, como difundido e positivado no art. 1.796 do Código Civil, divide-se em dois grandes ramos: a sucessão legítima e testamentária. A primeira é calcada no princípio da solidariedade e a segunda, na autonomia privada.

A sucessão legítima decorre de lei, que está alheia à vontade, bem como dos afetos e desafetos do morto. Fundamenta-se nos deveres de solidariedade para que o patrimônio do morto possa contribuir de maneira efetiva para a continuidade do sustento dos herdeiros: pode ocorrer que o de cujus, quando vivo, exercesse papel fundamental na subsistência da família, proporcionando uma vida digna aos seus membros. Por isso, mesmo que estejamos a tratar de um patrimônio adquirido com o trabalho e esforço pessoal do falecido, sua vontade não tem ingerência sobre parcela deste mesmo patrimônio, que é direcionado, por lei, aos familiares. Já que o Direito das Sucessões conjuga o direito de propriedade com o Direito de Família, justifica-se, desta forma, a sucessão legítima em fatores atrelados à proteção, coesão e perpetuidade da família. ${ }^{49}$

A sucessão testamentária, por seu turno, fundamenta-se na vontade, na liberdade de atribuir ao seu patrimônio a finalidade que seu titular julgar mais conveniente após a sua morte. Trata-se de aplicação da autonomia privada no âmbito patrimonial, de inegáveis reflexos existenciais, considerando que o testador terá segurança - garantida pelas exigências formais para a elaboração do testamento - de que a sua vontade produzirá os efeitos pretendidos após a sua morte, caso tenha havido o atendimento a todos os pressupostos exigidos por lei para a validade e eficácia do testamento.

Ocorre que o ordenamento jurídico prevê uma série de regras para a convivência desses dois tipos de sucessões, principalmente quando existem herdeiros necessários que, segundo o art. 1.845 do Código Civil, são os descendentes, ascendentes e cônjuge. Nesse caso, lhes é resguardada a legítima, ou seja, o mínimo de 50\% do patrimônio do falecido,

\footnotetext{
${ }^{49}$ Caio Mário da Silva PereIRA. Instituições de direito civil, vol. VI, 15. ed., atualizada por José Carlos BARbosa MoreIRA. Rio de Janeiro: Forense, 2004, p. 8.
} 
conforme art. 1.789, CC. ${ }^{50}$ A vontade do testador pode prevalecer abrangendo a totalidade do patrimônio, portanto, apenas quando inexistir herdeiros necessários.

Ana Luiza Maia Nevares afirma existir o princípio da intangibilidade da legítima, tendo em vista que, por ser a herança direito fundamental dos herdeiros (art. $5^{\circ}, \mathrm{XXX}$, $\mathrm{CF} / 88$ ), esta não pode deles ser retirada por mera vontade do testador, pois a sucessão legítima decorre do princípio da solidariedade. Logo, a legítima é intangível e qualquer limitação que nela possa vir a existir só pode ser fruto de uma decisão que beneficie os próprios herdeiros. Nesse sentido, sugere a autora interpretação do art. 1.848, CC, que tutele os herdeiros: quando este dispositivo determina que pode o testador apor cláusulas restritivas de propriedade (inalienabilidade, impenhorabilidade e incomunicabilidade) na parte legítima da herança, que só poderá se efetivar caso haja uma justa causa para tal restrição. Essa justa causa - conceito jurídico indeterminado - segundo a autora, deve estar ligada ao patrimônio mínimo do herdeiro, ou seja, a alguma razão que lhe tutele "a partir da indisponibilidade de um bem essencial" à pessoa, por existir razões justificadoras para tais restrições. ${ }^{51}$ Logo, mesmo a restrição da propriedade - cuja atribuição deu-se por motivos cuja ratio baseia-se na solidariedade social - encontra guarida no princípio da solidariedade, tendo em vista que, em matéria patrimonial, a função social dos bens deve preponderar sobre a autonomia da pessoa humana, a princípio.

Coexistem assim, no direito das sucessões, de forma equilibrada, a liberdade do morto de destinar seu patrimônio para quem ele deseja com a necessidade de proteção aos membros mais próximos da família. Todavia, é necessário refletir como este equilíbrio constitucionalmente imposto no tocante à legítima se projeta sobre disposições para depois da morte de natureza existencial. Fora da esfera patrimonial, seria possível ampliar a liberdade testamentária do testador? Seria viável, neste âmbito, pensar na liberdade plena de testar ou esse direito deve ser mitigado em prol da proteção à família? ${ }^{52}$

\footnotetext{
50 “Percebe-se, portanto, que o instituto da legítima encontra seu fundamento na conciliação entre o princípio da liberdade do proprietário dos bens e o direito dos parentes próximos à sucessão, ou seja, entre a plena liberdade de testar e a proteçao à família, afirmando Pontes de Miranda que "no fundo, conciliam-se os interesses da família e os interesses provindos de amizade e gratidão'." (Ana Luiza Maia NEVARES, O princípio da intangibilidade da legítima. In: Maria Celina Bodin de MorAes, Princípios do direito civil contemporâneo. Rio de Janeiro: Renovar, 2006, p. 501)

51 Ana Luiza Maia Nevares, O princípio da intangibilidade da legítima. In: Maria Celina Bodin de MoRAES, Princípios do direito civil contemporâneo. Rio de Janeiro: Renovar, 2006, p. 532.

${ }^{52}$ Ana Luiza Maia Nevares, O princípio da intangibilidade da legítima. In: Maria Celina Bodin de MorAES, Princípios do direito civil contemporâneo. Rio de Janeiro: Renovar, 2006, p. 543.
} 
A resposta, aqui, deve ser positiva. A influência do princípio da dignidade da pessoa humana sobre o direito sucessório tem se materializado no que pode ser chamado, nas palavras de Ana Luiza Maia Nevares, a função promocional do testamento. ${ }^{53}$ Tradicionalmente entendido como o ato egoísta e puramente subjetivo de dispor do patrimônio para depois da morte, sob a ótica civil-constitucional, as disposições de última vontade podem ter conteúdo existencial e servir à realização de interesses merecedores de tutela, referentes a direitos da personalidade ou relativas à filiação.

Nesta linha, defende-se também o chamado "testamento vital", no qual as disposições não tem por objeto efeitos posteriores à morte, mas os cuidados e tratamentos que lhe serão aplicáveis em estado terminal quando não mais puder exprimir vontade. ${ }^{54}$ Nesta seara, já se concluiu que, diante dos princípios da dignidade e da liberdade, são válidas e eficazes tais disposições, uma vez que asseguram a implementação da vontade do paciente terminal. $^{55}$

Portanto, a legitimação conferida pela lei aos familiares não pode ser entendida como uma prerrogativa para substituir a expressa vontade do de cujus pela sua. É inconcebível que aquilo que foi considerado uma expressão de liberdade e solidariedade do de cujus em vida seja, depois da sua morte, reputado uma afronta à sua dignidade, idônea a legitimar seus familiares a fazerem com que cesse. Mesmo porque sua liberdade de escolha pode ser ampla o suficiente para fazer designações existenciais, que coincidam com suas crenças e ideais, para após a sua morte. Isso significa que a autonomia privada tem dimensões espaciais que ultrapassam a existência da pessoa humana e do sujeito de direitos abstrato. Não parece compatível com nossa tábua principiológica permitir que a família considere o gesto livre e solidário do doador/testador uma lesão à sua própria dignidade.

Assim, seja em questões afetas à doação de órgãos ou aos testamentos - dentro dos limites formais e materiais impostos pela lei - não há dúvidas de que deve prevalecer a vontade da própria pessoa, que em atos autônomos e responsáveis, traça diretrizes para seu

\footnotetext{
53 Ana Luiza Maia NeVAREs. A função promocional do testamento. Rio de Janeiro: Renovar, 2009.

${ }^{54}$ Caio Mário da Silva PEREIRA. Insituições de direito civil, vol. VI, 17. ed., atualizada por Carlos Roberto Barbosa Moreira.. Rio de Janeiro: Forense, 2009. p. 181.

55 Ana Carolina Brochado TeIXEIRA e Luciana Dadalto PENALVA. Terminalidade e autonomia: uma abordagem do testamento vital no direito brasileiro. In Tânia da Silva Pereira et al. (coord.). Vida, morte e dignidade humana. Rio de Janeiro: GZ, 2010, p. 79.
} 
corpo e seus bens para que tenham em um momento em que ela não tenha condições mais de decidir, seja por estar em situação de grave doença, ou por já ter falecido.

\section{A relevância da declaração de vontade do doador para o transplante de órgãos depois da morte}

Retomando a questão da doação de órgãos, no contexto atual temos, portanto, de um lado um dispositivo especial (art. $4^{\circ}$ da Lei de Transplantes) que determina que a doação de órgãos e tecidos depois da morte só pode ocorrer com autorização da família. De outro lado, temos um dispositivo posterior (art. 14 do Código Civil) que assevera a validade da disposição gratuita do próprio corpo para depois da morte com fim altruístico ou científico.

Não há dúvidas de que a família, no momento em que é consultada sobre o transplante, sofre o dramático impacto da perda do ente querido. Mas é exatamente por isso que não deve caber a ela de forma absoluta, em qualquer hipótese, a decisão final acerca da doação de órgãos - principalmente se o falecido manifestou sua vontade. Seria cruel exigir dos familiares, neste momento traumático, o desprendimento para autorizar o transplante. ${ }^{56}$ Deve caber a ela sim, a decisão, no caso de silêncio do falecido, pois representam o que está mais próximo do que seria sua própria manifestação. Todavia, expresso em vida o desejo de doar seus órgãos, esta declaração deve ser reputada válida independente do consentimento dos familiares.

Neste sentido, entre os doutrinadores do direito civil, já se afirmou:

Entende-se prevalecente a interpretação que favorece o art. 14 do novo Código em virtude, principalmente, de sua adequação com o princípio constitucional da dignidade da pessoa humana, o qual garante à pessoa, em lugar de aos seus parentes, o direito de dispor sobre o destino de seu próprio corpo..$^{7}$

Na mesma linha, o enunciado n. 277, aprovado na IV Jornada de Direito Civil, promovida pelo Centro de Estudos Judiciários do Conselho da Justiça Federal, em 2006:

$\mathrm{O}$ art. 14 do Código Civil, ao afirmar a validade da disposição gratuita do próprio corpo, com objetivo científico ou altruístico, para depois da morte, determinou

\footnotetext{
${ }^{56}$ Constata-se que os familiares são afligidos, no mais das vezes, diante da dramática e súbita sensação de perda e de vivência do luto, por sentimentos reprimidos de raiva pelo abandono e pelos transtornos deixados, de culpa pela impossibilidade de ter viabilizado a salvação, de vergonha, pela doença ou desastre na família, de castigo, por antigas faltas ou pecados. Sobre o tema, v. David ZIMERMAN. A dignidade diante da morte, sob a ótica de um psicanalista. In Tânia da Silva Pereira et al. (coord.). Vida, morte e dignidade humana. Rio de Janeiro: GZ, 2010, p. 133-134.

57 Caio Mário da Silva PereIRA. Instituições de Direito Civil, vol. I, 22. ed., atualizada por Maria Celina Bodin de MORAES. Rio de Janeiro: Forense, 2007, p. 224.
} 
que a manifestação expressa do doador de órgãos em vida prevalece sobre a vontade dos familiares, portanto, a aplicação do art. $4^{\circ}$ da Lei n. 9.434/97 ficou restrita à hipótese de silêncio do potencial doador.

Entre os dois dispositivos, portanto, considerando que a família desempenha um papel instrumental no tocante ao livre desenvolvimento da personalidade de seus membros e que a decisão de doar os próprios órgãos depois da morte é um ato de autonomia privada existencial que é amparado tanto pelo princípio da liberdade como da solidariedade, devese concluir pela prevalência do dispositivo do Código Civil. 